\title{
Glicerina bruta e caroço de algodão em suplementos múltiplos para terminação de bovinos à pasto na época das águas. Análise econômica
}

\author{
Possamai, A.J. ${ }^{1}$; Zervoudakis, J.T. ${ }^{\text {; }}$ Cabral, L.S. ${ }^{\text {; }}$ Oliveira, A.S. ${ }^{2}$; Hatamoto-Zervoudakis, L.K. ' ; Freiria, L.B. ${ }^{\text {; }}$; Donida, E.R. ; \\ Koscheck, J.F.W.' ${ }^{3}$ Silva, P.I.J.L.R.' ${ }^{1}$ e Melo, A.C.B.'
}

\author{
'Universidade Federal de Mato Grosso. Campus Universitário de Cuiabá. Boa Esperança. Cuiabá. MT. Brasil. \\ ${ }^{2}$ Universidade Federal de Mato Grosso. Campus Universitário de Sinop. Sinop. MT. Brasil. \\ ${ }^{3}$ Universidade Estadual Paulista. Campus Jaboticabal. Jaboticabal. SP. Brasil.
}

\section{PALABRAS CLAVE ADICIONALES}

Brachiaria brizantha.

Desempenho.

Pecuária.

Rentabilidade.

Terminação.

\section{RESUMO}

Objetivou-se avaliar o impacto da inclusão de caroço de algodão e glicerina bruta em suplementos múltiplos para bovinos em terminação na época das águas, sobre o desempenho produtivo e econômico da suplementação e aumento no peso de abate. Foram utilizados 40 bovinos, Nelore, machos, não castrados, distribuídos aleatoriamente em 4 grupos que receberam oferta média de $0,75 \%$ do peso corporal em suplemento, pela formulação padrão $(\mathrm{SP})$, inclusão de $15 \%$ de glicerina bruta $(\mathrm{GLIC})$, inclusão de $25 \%$ de caroço de algodão (CA) ou inclusão de $15 \%$ de glicerina bruta e $25 \%$ de caroço de algodão (CAGLIC). Não houve influencia $(p>0,05)$ sobre desempenho, peso de carcaça quente ou rendimento de carcaça. $\mathrm{O}$ incremento no peso de abate, mostrou-se favorável economicamente, independente da formulação utilizada, embora a maior rentabilidade tenha sido alcançada pelo fornecimento do suplemento CAGLIC dado ao menor custo do suplemento e manutenção do desempenho. A renda pode variar de acordo com os preços dos ingredientes padrões, devendo estes fatores ser considerados para a elaboração de suplementos múltiplos para bovinos em engorda a pasto no período das águas.

\section{Crude glycerin and cottonseed in multiple supplements for finishing cattle in grazing in the rainy season. Economic analysis}

\section{SUMMARY}

\section{ADDITIONAL KEYWORDS}

Brachiaria brizantha.

Performance.

Livestock.

Profitability.

Finish.

\section{INFORMACIÓN}

Cronología del artículo.

Recibido/Received: 10.2.2014

Aceptado/Accepted: 11.3.2015

On-line: 10.6 .2015

Correspondencia a los autores/Contact e-mail:

possamai.a.j@gmail.com

\section{INTRODUÇÃO}

É crescente o interesse pela intensificação da pecuária de corte, com redução na idade de abate, maior giro de capital além de melhor qualidade da carne produzida, neste sentido, o fornecimento de suplementos múltiplos em torno de $0,8 \%$ do peso corporal (PC) é fundamental para produção de animais com bom acabamento de carcaça em idade reduzida. No entanto, a flexibilidade na formulação do suplemento é de grande importância na manutenção da economicidade da atividade pecuária (Paulino et al., 2002).

Os elevados custos das commodities agrícolas, aliadas a necessidade de se buscar alternativas alimentares que não concorram com a alimentação humana ou de animais não ruminantes, desperta o interesse para coprodutos da agroindústria na tentativa de reduzir os 
custos, manter o desempenho animal e aumentar a rentabilidade do sistema produtivo (Parsons et al., 2009).

Neste cenário destacam-se a glicerina bruta, ingrediente rico em glicerol, unidade energética rapidamente fermentada a propionato no rúmen e convertido a glicose no fígado (Mach et al., 2009), e o caroço de algodão, alimento proteico, rico em ácidos graxos e fibra, que apresenta grande potencialidade para ser utilizado com alimento para ruminantes (Conner e Richardson, 1987).

Outro ponto importante a ser pontuado é a necessidade de elevação no peso de carcaça, que possibilita o aumento na produção de carne mesmo sem haver crescimento no rebanho. Além de que, a proporção de cortes comerciais em relação aos componentes não carcaça, são aumentados à medida que se incrementa o peso da carcaça (Missio et al., 2013), especialmente em animais Nelore não castrados onde a maior deposição de gordura e terminação da carcaça só são alcançados em maiores pesos corporais (Pazdiora et al., 2013). Neste sentido, é importante salientar que o incremento no peso de carcaça pode aumentar a receita líquida para o produtor, desde que o custo da arroba produzida, seja inferior ao preço de comercialização ao frigorifico.

Objetivou-se avaliar a inclusão da glicerina bruta associada ao caroço de algodão em suplementos múltiplos para Touros jovens Nelore na fase de engorda, avaliando-se a economicidade das formulações alternativas e da elevação no peso de abate destes animais, mantidos à pasto.

\section{MATERIAL E MÉTODOS}

O experimento foi conduzido no setor de produção de bovinos à pasto, unidade experimental da Universidade Federal de Mato Grosso - UFMT, localizada no município de Santo Antônio do Leverger - MT, distante $30 \mathrm{~km}$ do município de Cuiabá, no período chuvoso de dezembro a março 2013, totalizando 84 dias de experimento.

Aárea experimental destinada aos animais foi constituída de oito piquetes de 1,45 ha cada (área total de 11,6 ha), cobertos uniformemente com Brachiaria brizanha cv. Marandu, providos de bebedouros e comedouros cobertos para fornecimento do suplemento que permitem acesso simultâneo de todos os animais.

Foram utilizados 40 bovinos, machos, não castrados, Nelore, com idade média de 30 meses, distribuídos em lotes de 5 animais. Cada formulação de suplemento foi fornecida para dez animais, alocados em dois piquetes distintos, totalizando cinco animais por piquete, as replicas de piquete visaram reduzir possíveis efeitos relacionados a oferta e qualidade da forragem nos piquetes. Cada lote de cinco animais foi sorteado randomicamente para piquete e formulação de suplemento.

Os suplementos avaliados (tabela I) foram denominados por suplemento padrão (SP), constituído por ingredientes tradicionais, suplemento com 15\% de inclusão de glicerina bruta (GLIC), suplemento com inclusão de $25 \%$ de caroço de algodão (CA) e o su-
Tabela I. Formulação e composição químicobromatológica do suplemento padrão (SP), inclusão de $15 \%$ de glicerina bruta (GLIC), inclusão de $25 \%$ de caroço de algodão (CA) e associação de $25 \%$ de caroço de algodăo e $15 \%$ de glicerina bruta (CAGLIC) no suplemento (Formulation and chemical composition of the standard supplement (SP), inclusion of $15 \%$ crude glycerin (GLIC), inclusion of $25 \%$ of cottonseed (CA) and associated $25 \%$ of cottonseed and $15 \%$ crude glycerin (CAGLIC) in the supplement).

\begin{tabular}{lcccc}
\hline & \multicolumn{4}{c}{ Suplementos } \\
\cline { 2 - 5 } Ingredientes & SP & GLIC & CA & CAGLIC \\
\cline { 2 - 5 } & \multicolumn{4}{c}{$\mathrm{g} / \mathrm{kg}$} \\
\hline Caroço de algodão & - & - & 250,00 & 250,00 \\
Glicerina bruta $^{1}$ & - & 150,00 & - & 150,00 \\
Milho triturado & 620,00 & 440,00 & 470,00 & 290,00 \\
Farelo de soja & 200,00 & 230,00 & 100,00 & 130,00 \\
Ureia: SA (9:1) & 20,00 & 20,00 & 20,00 & 20,00 \\
Núcleo mineral ${ }^{2}$ & 20,00 & 20,00 & 20,00 & 20,00 \\
Casquinha de soja & 140,00 & 140,00 & 140,00 & 140,00 \\
\hline Total & 1000 & 1000 & 1000 & 1000 \\
\hline MS (g/kg) & 941,5 & 923,6 & 938,9 & 924,8 \\
MM (g/kg) & 40,6 & 56,7 & 43,9 & 54,3 \\
PB (g/kg) & 211 & 223 & 215 & 204 \\
FDN (g/kg) & 210 & 202 & 256 & 274 \\
FDNcp (g/kg) & 111,4 & 96,3 & 139,4 & 183,4 \\
EE (g/kg) & 34 & 35 & 88 & 83 \\
\hline
\end{tabular}

${ }^{1}$ Composição: matéria seca 915 g/kg; Glicerol 831 g/kg, PB: ausente; Cinzas: $60 \mathrm{~g} / \mathrm{kg}$; EE: $16 \mathrm{~g} / \mathrm{kg}$; Metanol: $2 \mathrm{~g} / \mathrm{kg}$; Sódio: $5 \mathrm{~g} / \mathrm{kg}$. ${ }^{2}$ Níveis de garantia: Cálcio 198 g; Fósforo 87 g; Sódio 97,6 g; Magnésio $5,1 \mathrm{~g}$; Enxofre $12 \mathrm{~g}$; lodo 17,7 mg; Ferro $280 \mathrm{mg}$; Selênio $18 \mathrm{mg}$; Cobalto 80 mg; Manganês $527 \mathrm{mg}$; Flúor 870 mg; Cobre $1.250 \mathrm{mg}$ e Zinco $3.500 \mathrm{mg}$.

plemento com inclusão de $15 \%$ de glicerina bruta e $25 \%$ de caroço de algodão (CAGLIC). Os suplementos avaliados apresentavam em torno de $21 \%$ de proteína bruta (PB), seguindo a recomendação do sistema BRCORTE (Valadares Filho et al., 2010) para bovino, Nelore, macho, não castrado, com peso médio no período experimental de $530 \mathrm{~kg}$, em sistema de pastejo, ganho médio de peso $1300 \mathrm{~g} /$ dia, considerando pastagem com teor de PB em torno de $8,00 \%$ na matéria seca, para esta época do ano.

Os suplementos foram fornecidos diariamente às 10 horas, em quantidades equivalentes a $4 \mathrm{~kg} /$ animal, representando em média $0,75 \%$ do PC em oferta de suplemento, com base à matéria natural.

No primeiro dia do experimento e a cada 10 dias foram realizadas coletas de amostras de forragem, através do corte, a $5 \mathrm{~cm}$ do solo, de três áreas delimitadas por um quadrado metálico de $0,5 \times 0,5 \mathrm{~m}$, escolhidos na altura média da forragem medido em 50 pontos de cada diagonal do piquete, para a estimação da massa de forragem e a matéria seca potencialmente digestível(MSpd). A avaliação da forragem a ser ingerida pelos animais foi realizada por meio da simulação manual de pastejo, após observação do habito de pastejo dos animais, realizou-se a coleta manual de porções das plantas, semelhantes àquelas que os animais estavam ingerindo, procedimento realizado por apenas 
Tabela II. Disponibilidade de matéria seca (DMS), disponibilidade de matéria seca potencialmente digestível (DMSpd) e composição químicobromatológica da forragem durante o período experimental (Availability of dry matter (DMS), availability of potentially digestible dry matter (DMSpd) and chemical composition of forage during the experimental period).

\begin{tabular}{lrrrr}
\hline \multirow{2}{*}{ Descrição } & \multicolumn{4}{c}{ Mês } \\
& Dezembro & Janeiro & Fevereiro & \multicolumn{1}{c}{ Março } \\
DMS (kg/ha) & $7.551,97$ & $8.204,07$ & $7.014,28$ & $8.307,70$ \\
DMSpd (\% MS) & 80,34 & 76,04 & 75,26 & 68,57 \\
DMSpd (kg/há) & $6.067,05$ & $6.238,14$ & $5.278,72$ & $5.696,63$
\end{tabular}

B. brizantha 'Marandu' (Pastejo simulado) (g/kg MS)

\begin{tabular}{lrrrr}
\hline MS (g/kg MN) & 277,30 & 306,60 & 291,10 & 260,10 \\
MM & 70,70 & 65,50 & 67,70 & 72,60 \\
PB & 86,00 & 73,20 & 74,90 & 94,40 \\
PIDN & 31,10 & 35,50 & 40,00 & 46,20 \\
FDN & 644,70 & 642,70 & 628,40 & 638,20 \\
FDNCP & 476,70 & 546,60 & 554,00 & 573,00 \\
EE & 27,80 & 25,00 & 23,90 & 24,10 \\
FDNI & 116,10 & 94,90 & 95,20 & 98,40 \\
\hline
\end{tabular}

um técnico treinado durante o período experimental. Método que permite a obtenção de uma estimativa aceitável da forragem selecionada pelos animais (Moraes et al., 2005).

As amostras foram congeladas à $-20^{\circ} \mathrm{C}$, e analisadas as concentrações de matéria seca (método No 934.01), proteína bruta (PB, método No 954.01) e extrato etéreo (EE, método No 920.39) de acordo com a AOAC (1990). Para análise da concentração de fibra em detergente neutro (FDN), as amostras foram tratadas com alfa amilase termoestável, sem uso de sulfito de sódio, corrigidas para o resíduo de cinzas (Mertens, 2002) e para o resíduo de compostos nitrogenados (Licitra et al., 1996). As análises de FDN foram realizadas, utilizando sacos de TNT (tecido-não-tecido), com dimensões de $5 \mathrm{~cm} \times 5 \mathrm{~cm}$, manteve-se a relação média de $14 \mathrm{mg}$ de $\mathrm{MS} / \mathrm{cm}^{2}$ de tecido e $100 \mathrm{~mL}$ de detergente neutro/g de amostra seca ao ar. A concentração de FDNi nos alimentos e fezes foi obtida após incubação por um período de 240 horas (Casali et al., 2008). Tomou-se as médias de três coletas realizadas no mesmo mês, para acompanhamento mensal da qualidade da forragem disponível aos animais de Dezembro/2012 a março de 2013 (tabela II).

Os animais foram pesados no inicio e termino do período experimental para cálculo de desempenho, após jejum hídrico e sólido de 12 horas, a fim de minimizar o efeito do enchimento do trato gastrintestinal.

Os animais foram abatidos em matadouro frigorifico comercial no município de Cuiabá devidamente cadastrado no Serviço de Inspeção Federal (SIF), seguindo a normatização Regulamento da Inspeção Industrial e Sanitária de Produtos de Origem Animal - RIISPOA (Brasil, 1952), após a sangria, esfola, evisceração e divisão em duas meias carcaças, estas foram pesadas, para obtenção do peso de carcaça quente, que divido pelo peso corporal gerou o rendimento de carcaça quente.
A avaliação econômica foi realizada levando em consideração a suplementação com formulação tradicional como parâmetro de investimento, tendo em vista a remuneração do capital investido, dividindo-se a margem de lucro pelo investimento total envolvido no processo de suplementação.

Para tanto, considerou-se rendimento de carcaça de inicial de $53 \%$ uma vez que animais Nelore, macho, não castrado, com peso corporal de cerca $480 \mathrm{~kg}$ apresentam rendimento de carcaça médio em torno de $53 \%$ (Jorge et al., 1999; Leme et al., 2000; Costa et al., 2005; Climaco et al., 2006; Barros et al., 2009).

A receita bruta foi obtida através da multiplicação do ganho em equivalente carcaça pelo valor do $\mathrm{kg}$ de carcaça na região (US\$3,05), e as despesas foram obtidas através do custo total com pasto (US $\$ 7,46$ animal/mês), custo com mão de obra (salário mais encargos referentes ao regime trabalhista CLT), custo com sanidade (desverminação, vacinação contra clostridiose e raiva) totalizando investimento de US $\$ 75,42$ no período ou US\$ $0,89 /$ dia. O investimento em suplementação foi calculado pelo preço dos ingredientes adicionando custo operacional de mistura de entorno de US $\$ 0,03 \mathrm{~kg}$. A remuneração do investimento foi calculada pela taxa de juros na poupança média em 2013 $(0,41 \%$ ao mês). As cotações utilizadas foram tomadas no Estado de Mato Grosso no período de condução deste experimento e convertidas para dólares americanos, utilizando cambio de R \$ 2,01/US\$. A receita líquida foi obtida pela subtração do total de despesas, da receita bruta.

À partir desta análise econômica calculou-se o ganho mínimo em carcaça e em peso corporal necessário para obter a rentabilidade igual a caderneta de poupança. O rendimento de ganho foi calculado pelo ganho de carcaça em $\mathrm{kg} /$ dia dividido pelo ganho médio diário em peso corporal. A finalidade de tal analise é predizer, o ponto que a elevação no peso de abate não é viável economicamente, dado pelo rendimento igual ou inferior ao rendimento financeiro obtido pela poupança.

No entanto, a análise econômica pontual pode limitar que inferências sejam feitas, sobre possíveis oscilações de mercado (Simões et al., 2007). Desta maneira foram elaborados cinco cenários, com variações nos preços de milho e farelo de soja que são a base dos suplementos de formulação padrão. $\mathrm{O}$ cenário 1 apresenta milho e farelo de soja com menor cotação obtida em 2013 no estado, o cenário 2 o milho encontra-se no preço médio praticado ao longo do ano, mantendo o custo do farelo de soja, e o cenário 3 o milho tem seu custo baseado na maior cotação praticada no estado. Nos cenário 4 e 5 o milho encontra-se em seu preço médio enquanto o custo com farelo de soja aumenta.

Os dados referentes ao desempenho dos animais foram analisados utilizando o procedimento PROC MIXED dos SAS versão 9.2 pela análise de variância, levando em consideração nível de significância de $5 \%$. Para análise econômica não foi realizado teste estatístico, considerando a magnitude dos indicadores. 


\section{RESULTADOS E DISCUSSÃO}

A taxa de lotação média durante o período experimental foi de 4,06 UA.ha-1, mantendo-se a disponibilidade de matéria seca potencialmente digestível (MSpd) de $318 \mathrm{~kg}$ de MSpd/100 kg de PC (tabela II), que possibilitou pastejo de forma seletiva pelos animais, com maior aproveitamento da forragem disponível. A disponibilidade de matéria seca foi mantida ao longo do período experimental, demonstrando que a taxa de lotação foi adequada, para a manutenção da forragem disponível. Houve no entanto uma redução da MSpd, ao longo dos meses, influenciada provavelmente pela seleção ao pastejo de lamina foliar pelos animais, sendo assim a proporção de colmo pode ter aumentado. Nas amostras de pastejo simulado observou-se uma redução na teor de FDNi, que pode ser atribuída ao fato do surgimento de laminas foliares jovens a mediada que forragem foi consumida.

Desta maneira, a boa disponibilidade de forragem aliada ao fornecimento de nutrientes extras via a suplementação múltipla, possibilitou o bom desempenho dos animais (tabela III). No entanto, não houve influência ( $p>0,05)$, da inclusão de caroço de algodão e/ou glicerina sobre o desempenho dos animais. Demonstra-se, que do ponto de vista nutricional, pode-se empregar estas formulações em suplementos múltiplos para terminação de bovinos à pasto.

Constata-se na literatura, ausência de trabalhos que associem a glicerina ao caroço de algodão. Avaliando assim, de maneira isolada o fornecimento de 0,6 a $2 \mathrm{~kg} /$ dia de caroço de algodão em suplementos múltiplos para bovinos em pastejo, não influenciou no ganho médio diário que variou de 0,6 a $1 \mathrm{~kg} /$ dia descritos por Moraes et al. (2006) e Paulino et al. (2002), respectivamente. Fato atribuído por estes autores à manutenção do aporte de nutrientes ao animal, onde as alterações no metabolismo ruminal, não são suficientes para promover alterações no desempenho dos animais alimentados com este tipo de alimento.

Estudos realizados em confinamentos, com utilização de glicerina bruta em inclusão de 0,5 a 1,3 kg/ dia, demonstraram bom potencial de ganho de peso dos animais, descrevendo desempenho de 1,37 a 1,4 kg/dia. (Mach, et al., 2009; Ramos e Kerley, 2012;
Françoso et al., 2013). O que Amplia a necessidade do estudo da inclusão deste ingrediente para animais mantidos em pastejo.

No presente estudo, o consumo de caroço de algodão e de glicerina bruta foi de 1,0 e 0,6 kg/animal/dia, respectivamente. A manutenção no fornecimento e absorção dos nutrientes é a premissa básica para a manutenção no desempenho dos animais independente do ingrediente utilizado (Mach et al., 2009).

O rendimento de carcaça não diferiu com a inclusão de glicerina bruta ou caroço de algodão $(p>0,05)$, fato que pode ser justificado, pela composição de ganho ser a mesma (Keane e Allen, 1998), uma vez que o desempenho foi similar e os animais tinham homogeneidade no inicio do período experimental, com produção de carcaças com pesos e rendimento semelhantes. A composição do ganho é de extrema importância em comparações de diferentes dietas, principalmente em análises econômicas uma vez que o produtor é remunerado por peso de carcaça, desta maneira a avalição pura e simples do desempenho pode não ser a mais indicada, já que não expressa a quantidade de carcaça produzida (Climaco et al., 2006; Pazdiora et al., 2013).

É possível ainda afirmar que houve igualdade na composição de ganho de peso, já que o peso corporal inicial e final não diferiu. Além da ausência de efeito para peso de carcaça $(p>0,05)$ e principalmente rendimento de carcaça quente. Rendimento de carcaça em Nelore, macho, não castrados, acima de $56 \%$ reportados por Euclides -Filho et al. (1997), Vaz et al. (2013) e Pazdiora et al. (2013), como reflexo da menor idade de abate e maior peso de carcaça o incremento, portanto, no peso corporal aumenta a proporção de peso da carcaça em relação aos componentes não carcaças.

A eficiência produtiva é um dos pilares para que os negócios agropecuários possam atingir níveis satisfatórios de competitividade. Neste contexto, a busca pelo aumento na produção através de ganhos de produtividade, em detrimento do aumento do rebanho, tem levado a reestruturação dos sistemas produtivos de gado de corte. Essa reestruturação é baseada na eficiência produtiva, sendo diretamente relacionada com a eficiência econômica dos sistemas de produção (Simões et al., 2007).

Tabela III. Médias e desvios padrão do peso corporal inicial (PCI), peso corporal final (PCF), ganho médio diário (GMD), peso carcaça quente (PCQ) e rendimento de carcaça quente (RCQ) dos animais consumindo suplemento padrão (SP), ínclusão de $15 \%$ de glicerina bruta (GLIC), inclusão de $25 \%$ de caroço de algodão (CA) e associação de $25 \%$ de caroço de algodão e $15 \%$ de glicerina bruta (CAGLIC) (Means and standard deviations of initial body weight (PCI), final body weight (PCF), average daily gain (GMD), hot carcass weight (PCQ) and hot carcass yield (RCQ) of animals receiving standard supplement (SP), including $15 \%$ crude glycerin (GLIC), including $25 \%$ of cottonseed (CA) and Association of $25 \%$ of cottonseed and $15 \%$ crude glycerin (CAGLIC)).

\begin{tabular}{lcccc}
\hline \multirow{2}{*}{ Métricas } & \multicolumn{4}{c}{ Suplementos experimentais } \\
\cline { 2 - 5 } & $\mathrm{SP}$ & $\mathrm{CA}$ & $\mathrm{GLIC}$ & CAGLIC \\
\hline PCl $(\mathrm{kg}) \mathrm{ns}$ & $472,20 \pm 26,44$ & $472,80 \pm 13,87$ & $472,70 \pm 22,93$ & $473,50 \pm 30,35$ \\
PCF $(\mathrm{kg}) \mathrm{ns}$ & $583,70 \pm 39,20$ & $585,20 \pm 3,31$ & $584,60 \pm 30,93$ & $594,10 \pm 40,62$ \\
GMD (kg/dia)ns & $1,32 \pm 0,21$ & $1,33 \pm 0,16$ & $1,33 \pm 0,13$ & $1,43 \pm 0,24$ \\
PCQ (kg)ns & $328,70 \pm 30,83$ & $330,80 \pm 17,78$ & $328,60 \pm 16,86$ & $333,20 \pm 18,85$ \\
RCQ (\%)ns & $56,30 \pm 2,22$ & $56,52 \pm 1,77$ & $56,21 \pm 1,25$ & $56,08 \pm 1,20$ \\
\hline
\end{tabular}

ns - não significativo $(p>0,05)$ à analise de variância. 
Tabela IV. Custo dos ingredientes e suplemento padrão (SP), inclusão de $15 \%$ de glicerina bruta (GLIC), inclusão de 25 de caroço de algodão (CA) e associação de $15 \%$ de glicerina bruta e $25 \%$ de caroço de algodão (CAGLIC) suplementos utilizados expressos em US $\$ / \mathrm{kg}$ de matéria natural (MN) (Cost of ingredients and supplements standard supplement (SP), inclusion of $15 \%$ crude glycerin (GLIC), inclusion of 25 of cottonseed (CA) and associated $15 \%$ crude glycerin and $25 \%$ cottonseed (CAGLIC) used expressed in US $\$ / \mathrm{kg}$ of fresh matter (MN)).

\begin{tabular}{lccccc}
\hline & & \multicolumn{5}{c}{ Suplemento experimental } \\
\cline { 3 - 6 } Ingredientes $^{2}$ & US $\$ / \mathrm{kg}$ MN & SP & GLIC & CA & CAGLIC \\
\cline { 3 - 6 } & & \multicolumn{5}{c}{ US $\$ / \mathrm{kg} \mathrm{MN}$} \\
\hline Caroço de algodão & 0,20 & & & & \\
Glicerina & 0,05 & & & & \\
Milho triturado & 0,16 & & & & \\
Farelo de soja & 0,44 & 0,28 & 0,27 & 0,26 & 0,26 \\
Ureia:SA $^{3}$ & 0,79 & & & & \\
Núcleo mineral $^{4}$ & 0,74 & & & & \\
Casquinha de soja & 0,25 & & & &
\end{tabular}

${ }^{1}$ Adicionados US $\$ 0,03$ além dos custos com ingredientes referente ao operacional de mistura. ${ }^{2}$ Cotações coletadas no Estado de Mato Grosso durante o período experimental. ${ }^{3}$ Proporção de 9 partes de ureia pecuária para 1 parte de sulfato de amônio. ${ }^{4}$ Níveis de garantia: Cálcio 198 g; Fósforo 87 g; Sódio 97,6 g; Magnésio 5,1 g; Enxofre $12 \mathrm{~g}$; lodo $17,7 \mathrm{mg}$; Ferro 280mg; Selênio $18 \mathrm{mg}$; Cobalto $80 \mathrm{mg}$; Manganês 527 mg; Flúor 870 mg; Cobre 1.250 mg e Zinco 3.500 mg

O investimento com a alimentação dos animais, após sua aquisição representa o indicador econômico de maior importância na avaliação econômica da pecuária de corte, desta maneira, o conhecimento do custo da suplementação (tabela IV) tem grande valia no estabelecimento da estratégia mais apropriada para o sistema produtivo.

Adotou-se o peso inicial, final, ganho médio diário e rendimento de carcaça médio de todos os animais, uma vez que não houve diferença significativa entre os diferentes tipos de suplementação. A avaliação econômica da suplementação múltipla dos animais na época das águas (tabela V) mostrou resultado positivo, independente da formulação utilizada. Entretanto, as melhores viabilidades econômicas foram obtidas para a suplementação com caroço de algodão e/ou glicerina bruta, com redução no custo da arroba produzida na ordem de $1,38 \% ; 3,56 \%$ e $4,97 \%$ para os suplementos GLIC, CA e CAGLIC, respectivamente, em virtude do menor preço destes ingredientes quando comparados com alimentos tradicionais associada a manutenção do desempenho dos animais.

A receita líquida aumentou 4,49\%; 9,96\% e 14,44\% para a utilização dos suplementos GLIC, CA e CAGLIC, respectivamente, em virtude da redução nos custos de produção e manutenção da receita bruta. Dessa forma, constata-se aumento expressivo na receita liquida, especialmente quando se considera a situação atual da pecuária, em que a margem líquida de lucro esta cada vez menor, em virtude do aumento nos custos com mão de obra e aquisição ou locação de terras, além da grande concorrência com atividade agrícola e silvícola (Balbino et al., 2011).
Tabela V. Indicadores econômicos em da utilização do suplemento padrão (SP), inclusão de $15 \%$ de glicerina bruta (GLIC), inclusão de $25 \%$ de caroço de algodão (CA), e associação de $15 \%$ de glicerina bruta e $25 \%$ de caroço de algodão (CAGLIC) nas dietas de terminação função da formulação dos suplementos múltiplos (Economic indicators the use of standard supplement (SP), inclusion of $15 \%$ crude glycerin (GLIC), inclusion of $25 \%$ of cottonseed (CA), or association of $15 \%$ crude glycerin and $25 \%$ cottonseed (CAGLIC) in the finisher diets, according to the formulation of multiple supplements)

\begin{tabular}{|c|c|c|c|c|}
\hline \multirow{2}{*}{ Indicadores econômicos } & \multicolumn{4}{|c|}{ Suplemento avaliado } \\
\hline & SP & GLIC & CA & CAGLIC \\
\hline Valor inicial (US $\$ /$ animal) $)^{1}$ & 764,83 & 764,83 & 764,83 & 764,83 \\
\hline Peso carcaça inicial² & 250,65 & 250,65 & 250,65 & 250,65 \\
\hline Peso carcaça vendida ${ }^{3}$ & 330,30 & 330,30 & 330,30 & 330,30 \\
\hline Ganho em kg de carcaça ${ }^{4}$ & 79,65 & 79,65 & 79,65 & 79,65 \\
\hline Custo suplementação (US $\$)^{5}$ & 95,02 & 92,30 & 88,97 & 86,25 \\
\hline Outros custos (US $\$)^{6}$ & 75,42 & 75,42 & 75,42 & 75,42 \\
\hline $\begin{array}{l}\text { Remuneração investimento } \\
(\text { US } \$)^{7}\end{array}$ & 10,74 & 10,71 & 10,67 & 10,64 \\
\hline Total Investimento $(\mathrm{US} \$)^{8}$ & 181,18 & 178,42 & 175,06 & 172,31 \\
\hline $\begin{array}{l}\text { Custo kg de carcaça produzi- } \\
\text { da (US } \$)^{9}\end{array}$ & 2,27 & 2,24 & 2,20 & 2,16 \\
\hline Índice de custo $(\%)^{10}$ & 100,00 & 98,67 & 96,91 & 95,15 \\
\hline Receita bruta (US\$) $)^{11}$ & 1007,41 & 1007,41 & 1007,41 & 1007,41 \\
\hline Receita líquida (US \$) $)^{12}$ & 61,40 & 64,16 & 67,52 & 70,27 \\
\hline Índice de receita $(\%)^{13}$ & 100,00 & 104,49 & 109,96 & 114,44 \\
\hline Taxa de retorno/mês $(\%)^{14}$ & 2,32 & 2,43 & 2,57 & 2,68 \\
\hline Rentabilidade ha/mês ${ }^{15}$ & 75,66 & 79,05 & 83,19 & 86,59 \\
\hline $\begin{array}{l}\text { Mínimo GMD carcaça (kg/ } \\
\text { dia) }\end{array}$ & 0,67 & 0,65 & 0,64 & 0,63 \\
\hline Mínimo GMD PC $(\mathrm{kg} / \mathrm{dia})^{17}$ & 0,95 & 0,94 & 0,92 & 0,90 \\
\hline
\end{tabular}

${ }^{1}$ Valor inicial considerando $\mathrm{PCl}{ }^{*} 53 \% \mathrm{RCQ}$ * $\mathrm{R} \$ 6,13 / \mathrm{kg} .{ }^{2} \mathrm{PCl}$ * $53 \%$ RCQ. ${ }^{3}$ Peso carcaça no frigorífico. ${ }^{4}$ Peso carcaça vendida - peso carcaça inicial. ${ }^{5}$ Valor do suplementos * $4 \mathrm{~kg} / \mathrm{dia}$ * 84 dias. ${ }^{6} \mathrm{US} \$$ 7,46/mês referente a pasto + custo com funcionário contratado no regime CLT + investimento em sanidade (desverminação + vacinação contra clostridiose e raiva). ${ }^{7}$ Total do investimento considerando a remuneração de capital média da poupança $\left(0,41 \%\right.$ ao mês). ${ }^{8} \mathrm{Su}$ plementação + outros investimentos + remuneração do capital. ${ }^{9}$ Total de investimento $/ \mathrm{kg}$ carcaça produzido. ${ }^{10} \mathrm{Comparação} \mathrm{do} \mathrm{custo} \mathrm{do} \mathrm{kg}$ de carcaça produzida pelo suplemento padrão com as demais formulações. ${ }^{11}$ Peso carcaça vendidas * US \$ 3,05. ${ }^{12}$ Receita bruta - (Valor inicial do boi + custo da suplementação + Outros custos + remuneração investimento). ${ }^{13}$ Comparação da receita líquida da formulação padrão com as demais formulações. ${ }^{14}$ ((Receita líquida/investimento total $) / 84$ dias) ${ }^{*} 30$ dias. ${ }^{15}$ ((Receita líquida*lotação cab/ha)/84dias) *30 dias. ${ }^{16}$ Ganho Médio Diário (GMD) mínimo de carcaça para que a rentabilidade seja igual a taxa de retorno mensal da caderneta de poupança. ${ }^{17} \mathrm{GMD}$ em peso corporal para que o retorno do capital investido seja igual a da caderneta de poupança.

A viabilidade econômica da utilização de suplementos está intimamente relacionada com o desempenho animal. A disponibilidade de suplementos a baixo custo pode proporcionar a manutenção da rentabilidade do sistema produtivo, devendo-se atentar também para fatores ligados a logística e disponibilidade local dos ingredientes (Paulino et al., 2010).

Desta forma demonstra-se a, importância da viabilidade econômica na utilização de qualquer um dos suplementos, caracterizando a flexibilidade na tecnologia empregada, uma vez que o custo do $\mathrm{kg}$ de carcaça 
Tabela VI. Cenários de variação nos preços de milho e farelo de soja e custo do suplemento padrão (SP), inclusão de $15 \%$ de glicerina bruta (GLIC), inclusão de $25 \%$ de caroço de algodão (CÂ) e associação de $15 \%$ de glicerina bruta e $25 \%$ de caroço de algodão (CAGLIC) suplementos ofertados (Scenarios of change in the prices of the standard supplement (SP), inclusion of $15 \%$ crude glycerin (GLIC), inclusion of $25 \%$ of cottonseed (CA) and associated $15 \%$ crude glycerin and $25 \%$ cottonseed (CAGLIC) supplements offered).

\begin{tabular}{|c|c|c|c|c|c|}
\hline \multirow[t]{2}{*}{ Ingredientes } & Cenário 1 & Cenário 2 & Cenário 3 & Cenário 4 & Cenário 5 \\
\hline & \multicolumn{5}{|c|}{ US $\$ / \mathrm{kg} M N$} \\
\hline Caroço de algodão & 0,20 & 0,20 & 0,20 & 0,20 & 0,20 \\
\hline Glicerina & 0,05 & 0,05 & 0,05 & 0,05 & 0,05 \\
\hline Milho grão & 0,10 & 0,15 & 0,25 & 0,15 & 0,15 \\
\hline Farelo de soja & 0,37 & 0,37 & 0,37 & 0,50 & 0,60 \\
\hline Ureia: SA & 0,80 & 0,80 & 0,80 & 0,80 & 0,80 \\
\hline Sal mineral & 0,75 & 0,75 & 0,75 & 0,75 & 0,75 \\
\hline Casquinha de soja & - & 0,50 & 0,50 & 0,50 & 0,50 \\
\hline $\mathrm{SP}$ & 0,50 & 0,56 & 0,69 & 0,61 & 0,65 \\
\hline GLIC & 0,50 & 0,55 & 0,64 & 0,61 & 0,65 \\
\hline CA & 0,49 & 0,54 & 0,64 & 0,57 & 0,59 \\
\hline \multirow[t]{2}{*}{ CAGLIC } & 0,50 & 0,53 & 0,59 & 0,56 & 0,59 \\
\hline & \multicolumn{5}{|c|}{ Índice de retorno de capital $(\%)^{1}$} \\
\hline SP & - & - & - & - & - \\
\hline GLIC & 99,16 & 103,82 & 120,23 & 101,94 & 99,96 \\
\hline $\mathrm{CA}$ & 101,12 & 105,31 & 120,06 & 113,90 & 122,97 \\
\hline CAGLIC & 100,29 & 109,19 & 140,55 & 115,95 & 123,10 \\
\hline
\end{tabular}

${ }^{1}$ Índice de retorno de capital comparativo onde o fornecimento do suplemento padrão (SP) é considerado como base comparativa.

produzida foi em média US\$ 0,84 menor do que o valor venal do $\mathrm{kg}$ de carcaça que gerou, taxa mensal de retorno médio de $2,50 \%$, semelhante ao reportado por Coan et al. (2008) de 2,63\% de retorno do capital investido em confinamentos, de 2,22\% encontrado por Martha-Júnior et al. (2011) em sistemas integrados de lavoura pecuária e 2,36\% em sistemas intensificados de produção de bovinos à pasto (Barbosa et al., 2012).

A rentabilidade por área é um importante indicador de sucesso econômico da atividade, é o principal fator que faz produtores migrarem, para outras atividades agrícolas ou silvícolas (Martha-Júnior et al., 2011). Neste sentido, a tecnologia empregada no presente estudo foi responsável pelo retorno mensal médio por hectare de US \$ 81,12, fato atribuído à alta taxa de lotação utilizada e, ao baixo custo da arroba produzida.

Considerando-se que na época da seca a rentabilidade por área fosse $50 \%$ à encontrada na época das águas, o sistema geraria uma renda anual de US\$ 730,09 por hectare, demonstrando o quanto a pecuária de corte especialmente na fase de terminação pode ser rentável e competitiva com os demais ramos da agropecuária, maximizando o uso da terra e reduzindo o impacto ambiental pela maior produção de carne por unidade de área utilizada, além de redução na incorporação de novas áreas (Zervoudakis et al., 2011).

No tocante, a flexibilidade do sistema produtivo adequar-se às condições disponíveis, nas propriedades é relevante destacar o desempenho mínimo que os animais devem apresentar para que a rentabilidade do sistema seja igual a da poupança, ponto no qual não é mais interessante continuar a suplementação em virtude da baixa margem de retorno de capital investido.

Em cenários de baixos preços de milho e farelo de soja (tabela VI), a utilização de formulações alternativas não é economicamente interessante, este quadro muda a medida que o preço do milho aumenta, tornando as formulações alternativas mais atrativas economicamente.

Já em um cenário de milho a preço médio e aumento no custo do farelo de soja (cenários 4 e 5), a utilização do caroço de algodão tem maior impacto no aumento da receita, em relação a utilização da glicerina bruta ou da formulação padrão, uma vez que substitui parte do farelo de soja com decréscimo expressivo no custo dos suplementos CA e CAGLIC.

Portanto, a tomada de decisão sobre a formulação a ser utilizada em sistemas intensivos de produção de bovinos deve levar em consideração os preços dos principais ingredientes no suplemento, bem como a disponibilidade desses ingredientes alternativos, além de fatores ligados às logísticas destes produtos, para que a tecnologia empregada tenha sucesso e a rentabilidade maximizada.

\section{CONCLUSÃO}

O fornecimento de caroço de algodão e/ou glicerina bruta em suplementos múltiplos para animais Nelore, macho, não castrados no período das águas não influencia o peso final, ganho médio diário, peso de carcaça ou rendimento de carcaça.

O suplemento que mostrou maior viabilidade econômica foi o que associou o caroço de algodão e a glicerina bruta em sua formulação. 
Os preços dos ingredientes padrões devem ser considerados para tomada de decisão sobre qual formulação utilizar.

\section{BIBLIOGRAFIA}

A.O.A.C. 1990. Official Methods of Analysis. 15th Ed. Association of Official Analytical Chemists. Arlington. VA.

Balbino, L.C.; Cordeiro, L.A.M.; Silva, V.P.; Moraes, A.; Martínez, G.B.; Alvarenga, R.C.; Kichel, A.N.; Fontaneli, R.S.; Santos, H.P.; Franchini, J.C. e Galerani, P.R. 2011. Evolução tecnológica e arranjos produtivos de sistemas de integração lavoura-pecuária-floresta no Brasil. Pesq Agrop Bras, 46: 1-12.

Barbosa, F.A.; Souza, R.C.; Abreu, D.C.; Andrade, V.J. e Leão, J.M. 2010. Gerência e competitividade na bovinocultura de corte. In: Simpósio de Produção de Gado de Corte, 8, 2012. Anais ... SIMCORTE. Viçosa. pp. 159-182.

Barros, R.C.; Rocha Júnior, V.R.; Silva, F.V.; Alves, D.D.; Sales, E.C.J.; Franco, M.O.; Reis, S.T. e Souza, A.S. 2009. Cana-de-açúcar ou bagaço de cana amonizado com uréia em substituição à silagem de sorgo para bovinos de corte confinados. Rev Bras Saúde Prod Anim, 10: 278-292.

Brasil. 1952. Regulamento da Inspeção Industrial e Sanitária de Produtos de Origem Animal. Ministério da agricultura, pecuária e abastecimento. Brasília-DF: Departamento de Inspeção de Produtos de Origem Animal (DIPOA), Divisão de Normas Técnicas. Em: http://www.agricultura. gov.br/arq_editor/file/Aniamal/Mercadolnterno/Requisitos/Regulamentolnspecaolndustrial.pdf (13/11/2012).

Casali, A.O.; Detmann, E.; Valadares Filho, S. De C.; Pereira, J.C.; Herinques, L.T.; Freitas, S.G. De F. e Paulino, M.F. 2008. Influência do tempo de incubação e do tamanho de partículas sobre os teores de compostos indigestíveis em alimentos e fezes bovinas obtidos por procedimentos in situ. Rev Bras Zootecn, 37: 335-342.

Climaco, S.M.; Ribeiro, E.L.A.; Rocha, M.A.; Mizubuti, I.Y.; Silva, L.D.F.; Noro, L.Y. e Turini, T. 2006. Características de carcaça e qualidade de carne de bovinos inteiros ou castrados da raça Nelore, suplementados ou não durante o primeiro inverno. Ciên Rural, 36: 1867-1872.

Coan, R.M.; Reis, R.A.; Resende, F.D.; Sampaio, R.L.; Schocken-lturrino, R.P.; Garcia, G.R. e Berchielli, T.T. 2008. Viabilidade econômica, desempenho e características de carcaça de garrotes em confinamento alimentados com dietas contendo silagem de capins tanzânia ou marandu ou silagem de milho. Rev Bras Zootecn, 37: 311-318.

Conner, M.C. and Richardson, C.R. 1987. Utilization of cotton plant residues by ruminants. J Anim Sci, 65: 1131-1138.

Costa, M.A.L.; Valadares Filho, S.C.; Paulino, M.F.; Valadares, R.F.D.; Cecon, P.R.; Paulino, P.V.R.; Moraes, E.H.B.K. e Magalhães, K.A. 2005. Desempenho, digestibilidade e características de carcaça de novilhos zebuínos alimentados com dietas contendo diferentes níveis de concentrado. Rev Bras Zootecn, 34: 268-279.

Euclides Filho, K.; Euclides, V.P.B.; Figueiredo, G.R. eOliveira, M.P. 1997. Efeito da suplementação com concentrado sobre a idade de abate e características de carcaça de bovinos Nelore. Rev Bras Zootecn, 26: 1096-1102.

Françozo, M.C.; Prado, I.N.; Cecato, C.; Valero, M.V.; Zawadzki, F.; Ribeiro, O.L.; Prado, R.M. e Visentainer, J. 2013. Growth performance, carcass characteristics and meat quality of finishing bulls fed crude glycerin-supplemented diets. Braz Arch Biol Tech, 56: 327-336.

IMEA. 2013. Instituto Mato-Grossense de Pesquisa Agropecuária, Custo de Produção da Bovinocultura. Em: http://www.imea.com.br/publicacoes. php? categoria=2\&subcategoria=3 (05/12/2013).

Jorge, A.M.; Fontes, C.A.A.; Paulino, M.F.; Gomes Júnior, P. e Ferreira, J.N. 1999. Desempenho produtivo de animais de quatro raças zebuínas, abatidos em três estádios de maturidade. 2. Características da carcaça. Rev Bras Zootecn, 28: 381-387.

Keane, M.G. and Allen, P. 1998. Effects of production system intensity on performance, carcass composition and meat quality of beef cattle. Liv Prod Science, 56: 203-214.
Leme, P.R.; Boin, C.; Margarido, R.C.C.; Tedeschi, L.O.; Hausknecht, J.O.V.; Alleoni, G.F. e Luchicari Filho, A. 2000. Desempenho em confinamento e características de carcaça de bovinos machos de diferentes cruzamentos abatidos em três faixas de peso. Rev Bras Zootecn, 29: 2347-2353.

Licitra, G.; Hernandez, T.M. and Van Soest, P.J. 1996. Standardization of procedures for nitrogen fractionation of ruminant feeds. Anim Feed Sci Tech, 57: 347-358.

Mach, N.; Bach, A. and Devant, M. 2009. Effects of crude glycerin supplementation on performance and meat quality of Holstein bulls fed high-concentrate diets. J Anim Sci, 87: 632-638.

Martha Júnior, G.B.; Alves, E. e Contini, E. 2011. Dimensão econômica de sistemas de integração lavoura-pecuária. Pesq Agrop Bras, 46: 1117-1126.

Mertens, D.R. 2002. Gravimetric determination of amylase-treated neutral detergent fiber in feeds with refluxing in beaker or crucibles: collaborative study. J AOAC Inter, 85: 1217-1240.

Missio, R.L.; Restle, J.; Moletta, J.L.; Kuss, F.; Neiva, J.N.M. e Moura, C.F. 2013. Características da carcaça de vacas de descarte abatidas com diferentes pesos. Rev Ciên Agr, 44: 644-651.

Moraes, E.H.B.K.; Paulino, M.F.; Zervoudakis, J.T.; Valadares-Filho, S.C. e Moraes, K.A.K. 2005. Avaliação qualitativa da pastagem diferida de Brachiaria decumbens Stapf., sob pastejo, no período da seca, por intermédio de três métodos de amostragem. Rev Bras Zootecn, 34: 30-35.

Moraes, E.H.B.K.; Paulino, M.F.; Zervoudakis, J.T.; Valadares-Filho, S.C.; Cabral, L.S.; Detmann, E.; Valadares, R.D. e Moraes, K.A.K. 2006. Associação de diferentes fontes energéticas e protéicas em suplementos múltiplos na recria de novilhos mestiços sob pastejo no período da seca. Rev Bras Zootecn, 35: 914-920.

Parsons, G.L.; Shelor, M.K. and Drouillard, J.S. 2009. Performance and carcass traits of finishing heifers fed crude glycerin. J Anim Sci, 87: 653-657.

Paulino, M.F.; Detmann, E.; Valadares Filho, S. De C. e Lana, R. De P. 2002. Soja grão e caroço de algodão em suplementos múltiplos para terminação de bovinos mestiços em pastejo. Rev Bras Zootecn, 31: 484-491.

Paulino, M.F.; Detmann, E.; Valadares Filho, S.C.; Silva, A.G.; Cabral, C.H.A.; Valente, É.E.L.; Barros, L.V.; Paula, N.F.; Lopes, S.A. e Couto, V.R.M. 2010. Bovinocultura programa. In: Simpósio de Produção de Gado de Corte, 7, 2010. Anais ... SIMCORTE. Viçosa. pp. 281-312.

Pazdiora, R.D.; Resende, F.D.; Faria, M.H.; Siqueira, G.R.; Almeida. G.B.S.; Sampaio, R.L.; Pacheco, P.S. and Prietto, M.S.R. 2013. Animal performance and carcass characteristics of Nellore young bulls fed coated or uncoated urea slaughtered at different weights. Rev Bras Zootecn, 42: 273-283.

Ramos, M.H. and Kerley, M.S. 2012. Effect of dietary crude glycerol level on ruminal fermentation in continuous culture and growth performance of beef calves. J Anim Sci, 90: 892-899.

SAS. 2001. Institute Inc., SAS/STAT ® Software: Changes and Enhancements, Release 8.2. SAS Institute Inc. Cary, NC.

Simões, A.R.; Moura, A.D. e Rocha, D.T. 2007. Avaliação econômica comparativa de Sistemas de produção de gado de Corte sob condições de risco no Mato grosso do sul. Rev Econ Agr, 5: 51-72.

Valadares Filhos, S. De C.; Marcondes, M.I.; Chizzotti, M.L. e Paulino, P.V.R. 2010. Exigência nutricionais de zebuínos puros e cruzados BR-CORTE, $2^{a}$ ed. UFV, Suprema Gráfica Ltda. Viçosa, MG. 193 pp.

Vaz, F.N.; Restle, J.; Pádua, J.T.; Fonseca, C.A. e Pacheco, P.S. 2013. Características de carcaça e receita industrial com cortes primários da carcaça de machos Nelore abatidos com diferentes pesos. Ciên Anim Bras, 14: 199-207.

Zervoudakis, J.T.; Silva, L.C.R.P.; Silva, R.P.; Jose Neto, A.; Werner, J.F.K. e Silva, R.G.F. 2011 . Otimização do desempenho de bovinos por meio da suplementação à pasto. In: Simpósio Matogrossense de Bovinocultura de Corte. SIMBOV. Cuiabá. pp. 151-189. 
